\title{
rt-PA with Antithrombotic Therapies in a Case with Capsular Warning Syndrome
}

\author{
Yasuhiro Fuseya ${ }^{1,2}$, Miyuki Kawamura ${ }^{2}$, Eri Matsuda ${ }^{2}$, Kozue Takada $^{2}$, Kiwamu Watanabe $^{2}$, \\ Junko Fujitake ${ }^{2}$ and Yoshifumi Nakaya ${ }^{2}$
}

\begin{abstract}
We herein report a case of capsular warning syndrome (CWS) that was successfully treated with recombinant tissue plasminogen activator (rt-PA). A 70-year-old woman had repeated stereotyped transient ischemic attacks (TIAs) of right hemiparesis and dysarthria. After hospitalization, argatroban, aspirin, and cilostazol were started but were ineffective. Thirteen hours after the first episode of TIAs, severe symptoms occurred. Magnetic resonance imaging showed acute infarctions in the internal capsule to corona radiata, so we used rtPA. Since then, the TIAs have not occurred, and the symptoms have considerably improved. This case suggests that rt-PA might be effective and safe for use in treating CWS.
\end{abstract}

Key words: capsular warning syndrome, branch atheromatous disease, thrombolysis

(Intern Med 56: 441-444, 2017)

(DOI: 10.2169/internalmedicine.56.7522)

\begin{abstract}
Introduction
Capsular warning syndrome (CWS) is a rare clinical syndrome first described by Donnan et al. (1) in patients who had recurrent stereotyped episodes of transient ischemic attacks (TIAs). Among all TIA patients, only $1.5 \%$ have CWS (2), and the prognosis of CWS is poor. About $40 \%$ to $60 \%$ of CWS patients develop a cerebral infarction within 10 days $(1,2)$. Many different treatments have been proposed, such as multi-target antiplatelet therapies (3-6), a loading dose of clopidogrel $(4,5)$, and recombinant tissue plasminogen activator (rt-PA) (7-15), but no effective therapy has yet been established. In addition, the efficacy of rtPA on the outcome of CWS has not been determined.

Hemorrhaging is a typical complication of rt-PA for stroke patients but is rare for CWS $(8,14)$. We herein report a case of a CWS patient treated with rt-PA and antithrombotic therapies who had a good clinical course without any complications. In this case, rt-PA was effective and safe for a CWS patient.
\end{abstract}

Case Report

A 70-year-old woman with hypertension, dyslipidemia, and diabetes suddenly developed right hemiparesis and dysarthria at night. Her symptoms completely improved within 30 minutes, but because she had experienced the same episode 3 times, she was taken to our hospital. She had no history of drinking or smoking. Her blood pressure was $169 / 92 \mathrm{mmHg}$, there was no carotid bruit, and a neurological examination was normal when she arrived at our hospital. Within an hour of visiting our hospital, the same episode of transient right hemiparesis and dysarthria occurred twice.

The patient's complete blood cell and blood chemistry parameters were almost within normal limits. Carotid artery ultrasonography showed small isoechoic plaques on the right common carotid artery and left carotid bifurcation, and there was no obvious stenosis. Echocardiography and electrocardiogram revealed no abnormal findings. Magnetic resonance imaging (MRI) showed no acute cerebral infarctions. We diagnosed her with CWS, and she was hospitalized. We treated her with argatroban (60 mg/day), aspirin (100 mg/ day), cilostazol (200 mg/day), atorvastatin (10 mg/day), and

\footnotetext{
${ }^{1}$ Department of Neurology, Kyoto University Graduate School of Medicine, Japan and ${ }^{2}$ Department of Neurology, Kyoto City Hospital, Japan Received for publication April 5, 2016; Accepted for publication June 28, 2016

Correspondence to Dr. Yasuhiro Fuseya, fuseyay@kuhp.kyoto-u.ac.jp
} 

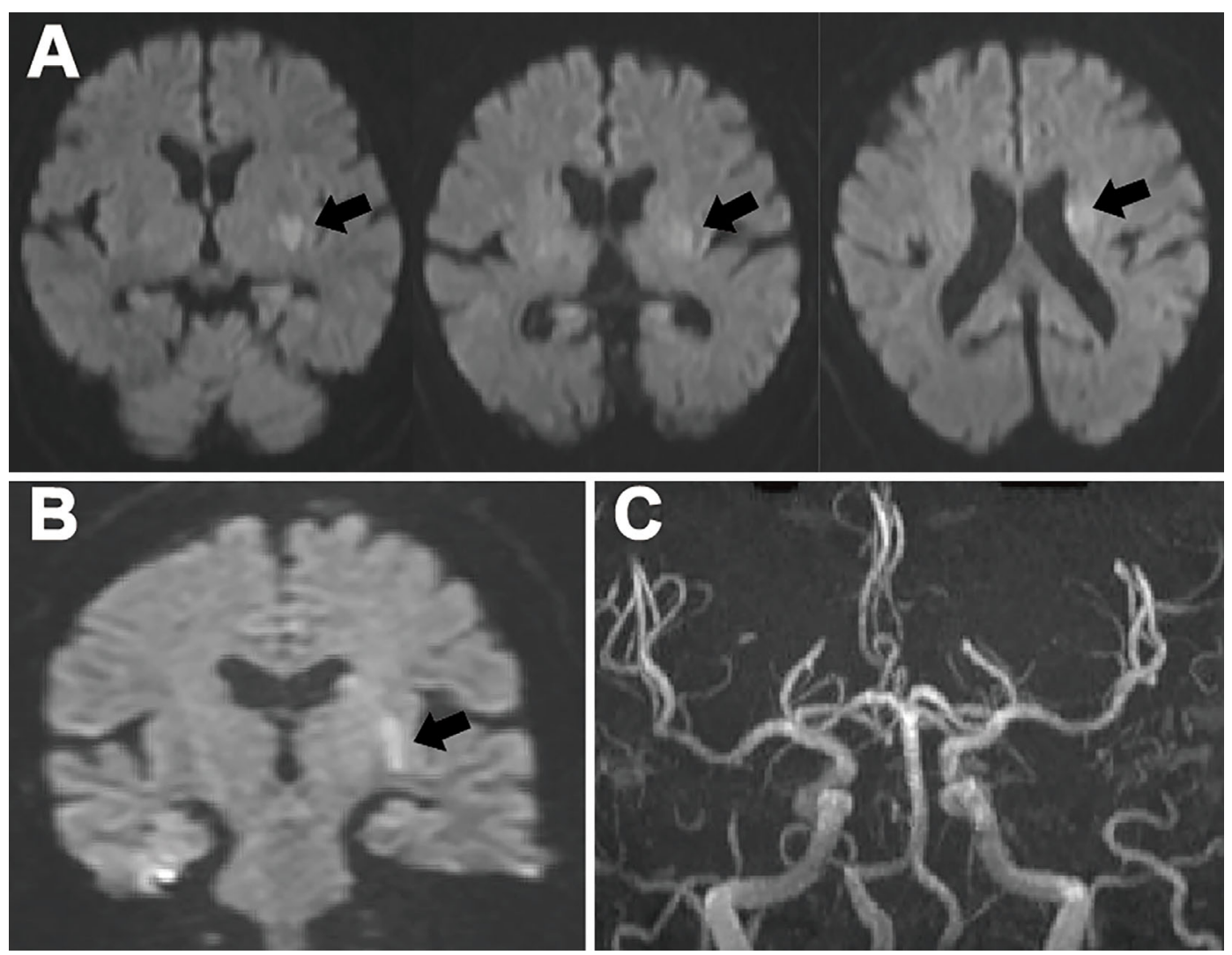

Figure 1. Brain magnetic resonance imaging (MRI) and MR angiography $13 \mathrm{~h}$ after the first episode of transient ischemic attacks. A: Diffusion-weighted imaging (DWI) axial view showing hyperintense areas in the left internal capsule to corona radiata (arrow). B: DWI coronal view showing hyperintense areas in the left internal capsule to corona radiata (arrow). C: MR angiography showing intact cerebral arteries.

edaravone $(60 \mathrm{mg} / \mathrm{day})$.

The treatments did not seem to be effective for her CWS in the acute phase. Thirteen hours after the first episode of TIAs, she developed more severe right hemiparesis and dysarthria, and her National Institute of Health Stroke Scale (NIHSS) score was 9 points. Diffusion-weighted imaging (DWI) on MRI showed slightly hyperintense areas in the left internal capsule to corona radiata (Fig. 1A, B), so we diagnosed her with acute cerebral infarctions. MR angiography did not detect any apparent stenosis of major cerebral arteries, including the left middle cerebral artery (Fig. 1C). We verified that there were no contraindications, obtained permission from the patient, and administered rt-PA 80 minutes after the most recent onset of neurological deficit. Her symptoms gradually improved, and her NIHSS score decreased to 3 points immediately after the end of rt-PA administration. TIAs have not occurred since then. The NIHSS score was 0 points 4 hours after the last onset of neurological deficit, although she still had slight right hemiparesis (Fig. 2). Over the course of administration, there were no marked changes in her blood pressure.

We verified that no bleeding was present using brain CT 24 hours after rt-PA administration and started argatroban, aspirin, and clopidogrel. The patient underwent rehabilitation, and her symptoms further improved, but she still had very slight right hemiparesis, and her modified Rankin Scale score was 2 points. She was transferred to a rehabilitation hospital on the 29th day after her hospitalization.

\section{Discussion}

The term "capsular warning syndrome" was coined in 1993 to describe patients who have recurrent stereotyped episodes of motor or sensory deficits without cortical symptoms (1). A recent study showed that infarct locations of CWS vary; $50 \%$ of CWS patients have infarctions in the internal capsule, but the other half have infarctions in other locations (14). As such, some researchers and clinicians have suggested that the term "capsular warning syndrome" might not be adequate, and "vascular warning syndrome" or "stroke warning syndrome" has been used in some recent reports $(8,14,15)$. Our patient had recurrent stereotyped episodes of TIAs, and MRI showed acute cerebral infarctions in the internal capsule to corona radiata, so we diagnosed her with CWS.

The pathophysiology of CWS has not yet been elucidated, but many hypotheses have been suggested, such as hemodynamic impairment owing to atherosclerotic severe stenosis of the proximal portions of the penetrating artery, microembolism from artery to artery or from the heart, vasospasm, 

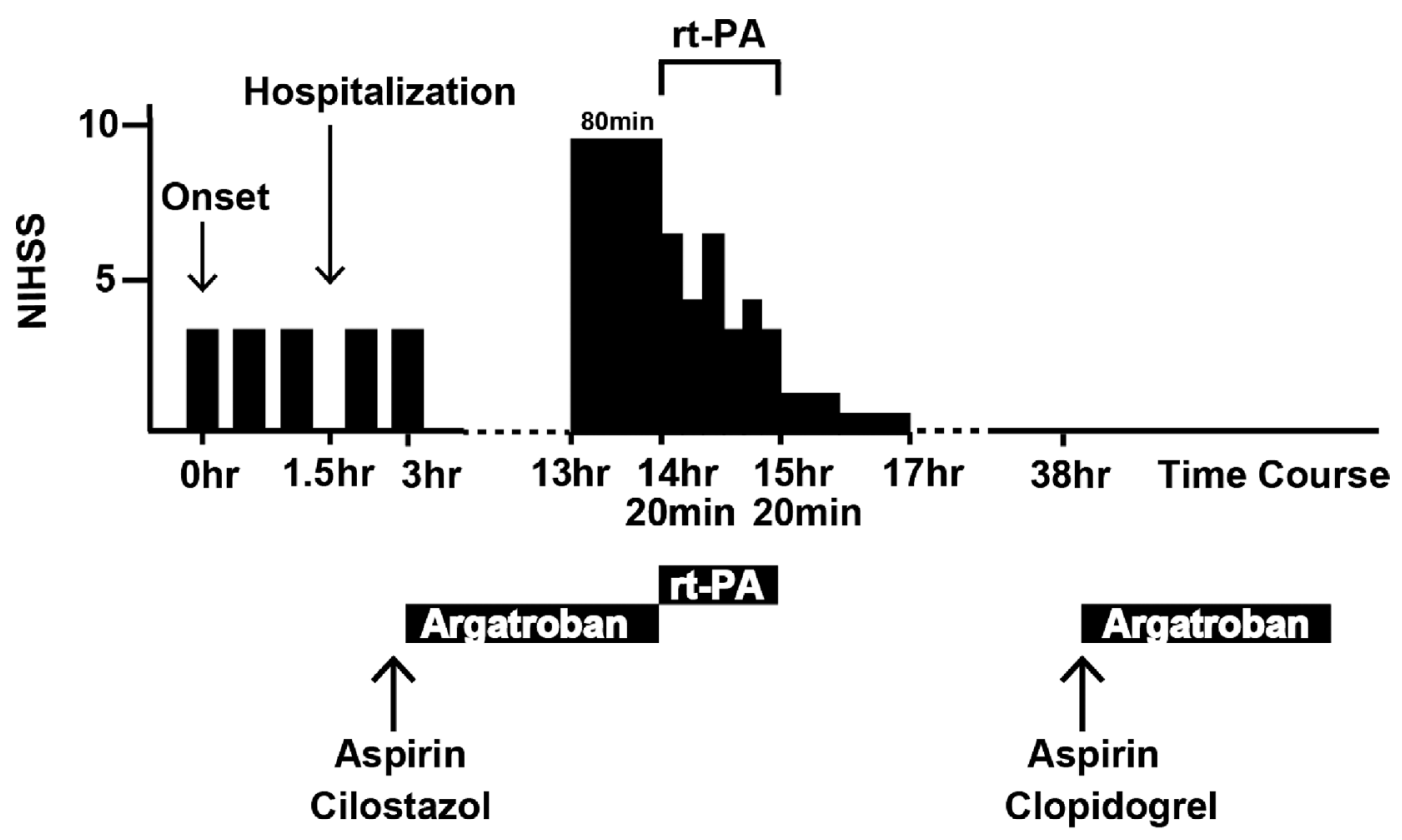

Figure 2. The clinical course of the patient. The horizontal bar shows the time course (hour); the vertical bar shows the National Institute of Health Stroke Scale (NIHSS) score.

or peri-infarct depolarizations $(6,16)$.

Our patient's infarctions were restricted to lenticulostriate arteries (LSAs) and were seated proximally along LSAs, so we concluded that this stroke type was branch atheromatous disease (BAD). BAD was first described in 1989 by Caplan (17) for an occlusion or stenosis at the origin of a deep penetrating artery of the brain leading to infarctions. The present patient had no obvious stenosis in the left middle cerebral artery, and we could not evaluate the LSAs by MR angiography. We speculate that there was atherosclerotic severe stenosis of the LSAs in the proximal position, which subsequently led to CWS and a BAD-type stroke.

No treatment for CWS has yet been established, and CWS patients have been treated in various ways. Classical therapy, including aspirin and heparin, is not sufficient $(1,16)$. In some reports, a loading dose of clopidogrel, with or without another antiplatelet therapy, is effective $(4,5)$. Intravenous thrombolysis therapy has also been used in some reports; Vivanco-Hidalgo et al. (11) reported that they treated four CWS patients with intravenous thrombolysis, and three of them made a full recovery, indicating that thrombolysis with rt-PA was effective for CWS. However, Tassi et al. (8) reported that rt-PA seemed to have lower efficacy than other therapies. Thus, the efficacy of intravenous thrombolysis is still controversial. Recent studies have reported that none of the CWS patients treated with rtPA showed any symptomatic bleeding complications, suggesting that rt-PA might be safe for the acute phase of CWS $(8,14)$.

We initially treated our patient with argatroban, aspirin, cilostazol, atorvastatin, and edaravone without rt-PA because no symptoms were present and no acute infarctions were observed with MRI. However, these therapies were ineffec- tive in the acute phase of CWS for the patient, and cerebral infarctions ultimately occurred. We immediately used rt-PA, which was very effective and had no complications. CWS has a high risk of developing cerebral infarctions, and when cerebral infarctions occurred in our patient, rt-PA was effective and safe.

As mentioned above, CWS is believed to be often caused by hemodynamic impairment due to atherosclerotic severe stenosis of the proximal portions of the penetrating artery. Typically, rt-PA is effective for fibrin clots. We therefore suggest that, in addition to atherosclerotic severe stenosis, unstable fibrin clots on the proximal portions of the penetrating artery may be involved in the pathophysiology of CWS, causing intermittent hypoperfusion and recurrent stereotyped TIAs.

Since 1993, many CWS cases have been reported, but the most effective therapy for CWS has not yet been determined. We herein reported a case of CWS that was successfully treated with rt-PA and other antithrombotic therapies. We found rt-PA to be effective without any complications. rt-PA may be an effective and safe treatment in CWS patients who develop cerebral infarctions.

The authors state that they have no Conflict of Interest (COI).

\section{References}

1. Donnan GA, O'Malley HM, Quang L, Hurley S, Bladin PF. The capsular warning syndrome: pathogenesis and clinical features. Neurology 43: 957-962, 1993.

2. Paul NL, Simoni M, Chandratheva A, Rothwell PM. Populationbased study of capsular warning syndrome and prognosis after early recurrent TIA. Neurology 79: 1356-1362, 2012. 
3. Asil T, Ir N, Karaduman F, Cagli B, Tuncel S. Combined antithrombotic treatment with aspirin and clopidogrel for patients with capsular warning syndrome: a case report. Neurologist 18: 68-69, 2012.

4. Fahey CD, Alberts MJ, Bernstein RA. Oral clopidogrel load in aspirin-resistant capsular warning syndrome. Neurocrit Care 2: 183-184, 2005

5. Kawano H, Nakajima M, Inatomi Y, Yonehara T, Ando Y. Loading dose of clopidogrel in combination with other antithrombotic therapy for capsular warning syndrome. J Stroke Cerebrovasc Dis 23: 1265-1266, 2014.

6. Makita N, Yamamoto Y, Nagakane Y, Ashida S, Mizuno T. Very prolonged capsular warning syndrome. J Neurol Sci 352: 115-116, 2015.

7. Muengtaweepongsa S, Singh NN, Cruz-Flores S. Pontine warning syndrome: case series and review of literature. J Stroke Cerebrovasc Dis 19: 353-356, 2010.

8. Tassi R, Cerase A, Acampa M, et al. Stroke warning syndrome: 18 new cases. J Neurol Sci 331: 168-171, 2013.

9. Saposnik G, Noel de Tilly L, Caplan LR. Pontine warning syndrome. Arch Neurol 65: 1375-1377, 2008.

10. Taguchi Y, Takashima S, Nukui T, Dougu N, Toyoda S, Tanaka K. Case of branch atheromatous disease presenting capsular warning syndrome. Rinsho Shinkeigaku 50: 320-324, 2010 (in Japanese, Abstract in English).

11. Vivanco-Hidalgo RM, Rodriguez-Campello A, Ois A, et al.
Thrombolysis in capsular warning syndrome. Cerebrovasc Dis 25: 508-510, 2008.

12. Gutiérrez Ruano B, García Pastor A, Villanueva Osorio JA, et al. Intravenous thrombolysis in capsular warning syndrome: is it beneficial? Neurologia 28: 444-446, 2013 (in Spanish).

13. Nicoli F, Faivre A, Squarcioni C, Combaz X, Girard N. Repeated MR-based intravenous thrombolysis in a patient with short interval stroke recurrences. J Neuroradiol 38: 256-258, 2011.

14. Camps-Renom P, Delgado-Mederos R, Martinez-Domeno A, et al. Clinical characteristics and outcome of the capsular warning syndrome: a multicenter study. Int J Stroke 10: 571-575, 2015.

15. Gonzalez Hernandez A, Fabre Pi O, Cabrera Naranjo F, Lopez Veloso AC. Intravenous thrombolysis with recombinant tissue plasminogen activator in vascular warning syndromes. Neurologia 29: 334-338, 2014.

16. Staaf G, Geijer B, Lindgren A, Norrving B. Diffusion-weighted MRI findings in patients with capsular warning syndrome. Cerebrovasc Dis 17: 1-8, 2004.

17. Caplan LR. Intracranial branch atheromatous disease: a neglected, understudied, and underused concept. Neurology 39: 1246-1250, 1989.

The Internal Medicine is an Open Access article distributed under the Creative Commons Attribution-NonCommercial-NoDerivatives 4.0 International License. To view the details of this license, please visit (https://creativecommons.org/licenses/ by-nc-nd/4.0/).

(C) 2017 The Japanese Society of Internal Medicine http://www.naika.or.jp/imonline/index.html 